\title{
Foreword
}

\section{Special issue: XXVI Brazilian Meeting on Particles and Fields}

This issue of the Brazilian Journal of Physics contains some papers presented at the plenary and parallel sessions of the XXVI Brazilian Meeting on Particles and Fields, which was held by the Brazilian Physics Society in São Lourenço, state of Minas Gerais, in Brazil, from 4 to 8 October, 2005 (the oral communications and posters were published electronically; see www.sbfisica.org.br/eventos/enfpc/xxvi). The conference was organized by a national committee with the following members: Ademir E. Santana (UnB), Alberto Saa (UNICAMP), Cláudio Furtado (UFPB), Fernando Brandt (USP), Fernando Marroquim Leão de Almeida (UFRJ; Chairman of the committee), Gastão Krein (ITF-UNESP), Hebe Queiroz (UFBA), João dos Anjos (CBPF), Magno Machado (UERGS), Maria Aline Barros (UFSJ), Nivaldo Lemos (UFF), and Sérgio Jorás (UDESC/UFRJ). There were five days of talks, poster presentations, and a round table discussion, bringing problems, advances, and new trends, in four basic research areas (cosmology and gravitation, quantum field theories, phenomenology, and experimental high energy physics). The meeting involved 323 participants, including senior researches, post-doctor fellows, and graduate students. It received financial support from CLAF (the Latin American Center of Physics) and federal and state Brazilian funding agencies (CNPq, CAPES, FINEP, FAPESP, FAPERJ, FAPERGS, and FAPEMIG).

Highlights of this conference included talks on particle physics with strong expectations about present and future situation at CERN/LHC; cosmic ray physics and the Pierre Auger observatory; developments in string and non-commutative field theory; studies on several elements of quantum field theory models, as the presence of confinement and asymptotical freedom in the Gross-Neveu model; aspects of QCD; Casimir effect and recent experimental achievements; the open problem of dark matter and energy; neutrino physics and the Angra Neutrino project. We still wish to emphasize that the conference was carried out at an outstanding level, and immersed in the spirit that we were also celebrating the World Year of Physics.

Finally, we would like to thank the talkers, for their contributions to this issue, the editor of the Braz. J. Phys., Professor Sílvio Salinas, for his support to the idea of editing the conference proceedings, and Ms. Neusa Martin, from the staff of the Braz. J. Phys., for her patience with us and for expertise in editing these proceedings.

Brasília, November 20, 2006

Guest Editors:

Fernando Marroquim Leão de Almeida Jr.

João dos Anjos

Sérgio E. Jorás

Ademir E. Santana 